\title{
Bioassay-guided isolation and identification of anti-obesity phytochemicals from fruits of Amomum tsao-ko
}

\author{
Seong Su Hong ${ }^{1 *}$ (), Chun Whan Choi ${ }^{1}$, Ji Eun Lee ${ }^{1}$, Yeon Woo Jung ${ }^{1}$, Jung A. Lee ${ }^{1}$, Wonsik Jeong ${ }^{1}$, \\ Yun-Hyeok Choi ${ }^{1}$, Hanna Cha', Eun-Kyung Ahn' ${ }^{1}$ and Joa Sub Oh ${ }^{2^{*}}$
}

\begin{abstract}
Amomum tsao-ko (Zingiberaceae), an important traditional medicinal herb, possesses many biological activities, including anti-inflammatory effects. Though the anti-obesity properties of the crude ethanol extract of $A$. tsao-ko fruits have been reported, the anti-adipogenic properties of its phytochemical constituents have not been reported. Therefore, in the present study, we isolated the active constituents of A. tsao-ko and investigated their anti-adipogenic effects. The bioassay-guided isolation of the phytochemicals from the ethanol extract of $A$. tsao-ko fruits identified four bioactive compounds, comprising one fatty acid (1), one sesquiterpene alcohol (2), and two phenolic compounds (3 and $\mathbf{4}$ ). Their structures were elucidated by a combination of 1D and/or 2D nuclear magnetic resonance and mass spectrometry. The anti-adipogenic activities of the four compounds evaluated by Oil Red O staining in 3T3-L1 cells revealed that the treatment with the isolated compounds $\mathbf{1}$ and $\mathbf{3}$ reduced the lipid accumulation in 3T3-L1 adipocytes more strongly than the compounds $\mathbf{2}$ and $\mathbf{4}$, in a dose-dependent manner.
\end{abstract}

Keywords: Amomum tsao-ko, Adipocyte differentiation, Oil red O staining, Phytochemicals, 3T3-L1 cells

\section{Introduction}

Obesity, the most common metabolic disease, is defined as a state of excess body fat accumulation that results from energy imbalance [1]. It is a serious public health problem implicated in various pathological disorders such as hypertension, type II diabetes, cardiovascular diseases, and certain cancers [2]. Generally, obesity involves the abnormal growth of adipocytes characterized either by hypertrophy (increase in cell size) or hyperplasia (increase in cell number) of fat-storing cells, and both are considered as therapeutic targets for the treatment of obesity [3]. The preadipocytes are the precursors of adipose depots that undergo complete differentiation into mature adipocytes. Therefore, it was hypothesized that

\footnotetext{
*Correspondence: bestgene@gbsa.or.kr; jsoh@dankook.ac.kr ${ }^{1}$ Bio-Center, Gyeonggido Business \& Science Accelerator (GBSA), Suwon 16229, Republic of Korea

${ }^{2}$ College of Pharmacy, Dankook University, Cheonan 31116, Republic of Korea
}

the suppression of adipogenesis, which is the development of mature adipocytes from fibroblastic preadipocytes, could reduce the accumulation of adipose tissue mass. Supporting this, Yun, using the 3T3-L1 cell lines, has shown that a reduction in the proliferation and differentiation of preadipocytes and an increase in triglyceride lipolysis in adipose tissue reduced the adipose lumps [4]. The 3T3-L1 cell lines are the preadipocyte cell lines derived from mouse embryonic fibroblasts and are the most commonly used in the study of adipogenesis and adipocyte differentiation in assay models in vitro [4]. Therefore, inhibition of fat accumulation by suppressing adipocyte differentiation is considered a key factor determining the potential of the anti-obesity agents.

Herbal extracts from plants, such as Moringa oleifera [5], Melissa officinalis [6], Vitis thunbergii var. taiwaniana [7], Pleurotus citrinopileatus [8], Nelumbo nucifera [9], and Melandrium firmum [10] have been reported to possess anti-obesity effects. In addition, several studies 
using the 3T3-L1 adipocyte cell lines have reported the anti-obesity and/or anti-adipogenic effects of different bioactive compounds, including isoflavone glycosides [11], phytosterols [12], oleane-type saponins [13], and cycloartane triterpene glycosides [14]. These studies indicated that crude drugs and natural products having the potential to reduce lipid accumulation would help solve the obesity problem worldwide.

Amomum tsao-ko Crevost et Lemaire (Zingiberaceae) is a perennial herb known for its use as a food additive (traditional Chinese spice) and in medicine $[15,16]$. Besides being an important spice, its dried fruit is commonly used to treat abdominal pain, dyspepsia, malaria, nausea, throat infections, stomach disorders, vomiting, and diarrhea in traditional medicine systems [17]. Recently, the fruits of $A$. tsao-ko have attracted attention as a functional food because of their various pharmacological properties [18-22]. In addition, diarylheptanoids and flavonoids, the major constituents of $A$. tsao-ko, have also demonstrated antioxidant, antitumor, anti-inflammatory, $\alpha$-glucosidase inhibitory activities, neuroprotective effects, and nitric oxide (NO) inhibitory effects [23-25].

As a part of an ongoing effort to discover naturally occurring anti-obesity agents from medicinal herbal extracts, our preliminary experiment revealed the potential of the ethanol extract of the fruits of $A$. tsao-ko in suppressing lipid accumulation in 3T3-L1 adipocytes [26]. However, its bioactive constituents responsible for the anti-obesity effects have not been investigated. Therefore, in this study, we aimed to isolate the active phytochemical constituents from the ethanol extract of $A$. tsao-ko fruit through bioassay-guided fractionation. In addition, we also aimed to elucidate the structures of the isolated compounds and evaluate their anti-adipogenic properties.

\section{Materials and methods Sample materials}

The fruits of A. tsao-ko were purchased from the Gyeongdong Oriental Medicine Market, Seoul, South Korea in February 2012, and identified by Professor Joa Sub Oh, College of Pharmacy, Dankook University, Cheonan, South Korea. A voucher specimen (G47) was deposited at the Natural Product Chemistry Laboratory, Bio-center, Gyeonggido Business \& Science Accelerator, Suwon, Korea.

\section{Reagents and instruments}

Optical rotations were measured using a JASCO P-2000 polarimeter (Tokyo, Japan). 1D $\left({ }^{1} \mathrm{H},{ }^{13} \mathrm{C}\right.$, and DEPT) and 2D $\left({ }^{1} \mathrm{H}-{ }^{1} \mathrm{H}\right.$ COSY, HSQC, and $\left.\mathrm{HMBC}\right)$ nuclear magnetic resonance (NMR) spectra were measured on a Bruker Ascend III 700 spectrometer (Bruker BioSpin GmbH., Rheinstetten, Germany) with tetramethylsilane as an internal standard, and chemical shifts were expressed as $\delta$ values. Electrospray ionization mass spectra (ESIMS) were obtained on an LTQ Orbitrap XL mass spectrometer (Thermo Fisher Scientific Inc., MA, USA). Gas chromatography-mass spectrometry (GC-MS) was carried out using a GCMS-QP2010 Ultra gas chromatograph interfaced with a single quadrupole QP-5000 mass spectrometer (Shimadzu Scientific Instruments Pty. Ltd., Tokyo, Japan). Preparative high-performance liquid chromatography (HPLC) was performed on a Shimadzu Prominence HPLC system with an LC-8A pump, SPD-20A UV/VIS detector, and YMC-Pack ODS A column $(250 \times 20 \mathrm{~mm}$ I.D. $)$, using a mixed solvent system of MeCN: Water at a flow rate of $12 \mathrm{~mL} / \mathrm{min}$. Mediumpressure liquid chromatography (MPLC) was conducted using a CombiFlash Rf flash chromatography system (Teledyne ISCO Inc., NE, USA), and the separations were performed on a RediSep ${ }^{\circledR} \mathrm{Rf}_{18}$ and silica gold column. Open column chromatography was performed using silica gel (Kieselgel 60, 70-230 mesh, Merck KGaA, Darmstadt, Germany), and thin-layer chromatography (TLC) was performed using a pre-coated silica gel 60 F254 (0.25 mm, Merck KGaA, Darmstadt, Germany). All chemicals and solvents were of analytical grade and were used without further purification.

\section{Extraction and isolation}

The dried fruits of $A$. tsao-ko (5 kg) were extracted with $80 \%$ aqueous ethanol $(3 \times 18 \mathrm{~L})$ at room temperature for 2 days and filtered. The extracts were combined and concentrated under reduced pressure to obtain a brown residue $(219 \mathrm{~g})$. The concentrate was suspended in $\mathrm{H}_{2} \mathrm{O}$ $(5 \mathrm{~L})$ and partitioned with EtOAc $(3 \times 5 \mathrm{~L})$. The EtOAcpartitioned sections $(30 \mathrm{~g})$ was separated by silica gel column chromatography and eluted with a gradient solvent system of $n$-hexane-acetone. The eluent was combined based on the TLC analysis to obtain nine fractions $\left(\mathrm{ATF}_{1}-\mathrm{ATF}_{9}\right)$. The solvent extracts and subfractions $\left(\mathrm{ATF}_{1}-\mathrm{ATF}_{9}\right.$ ) of $A$. tsao-ko fruits were screened for the adipogenesis inhibition assay at $12.5,25$, and $50 \mu \mathrm{g} /$ 


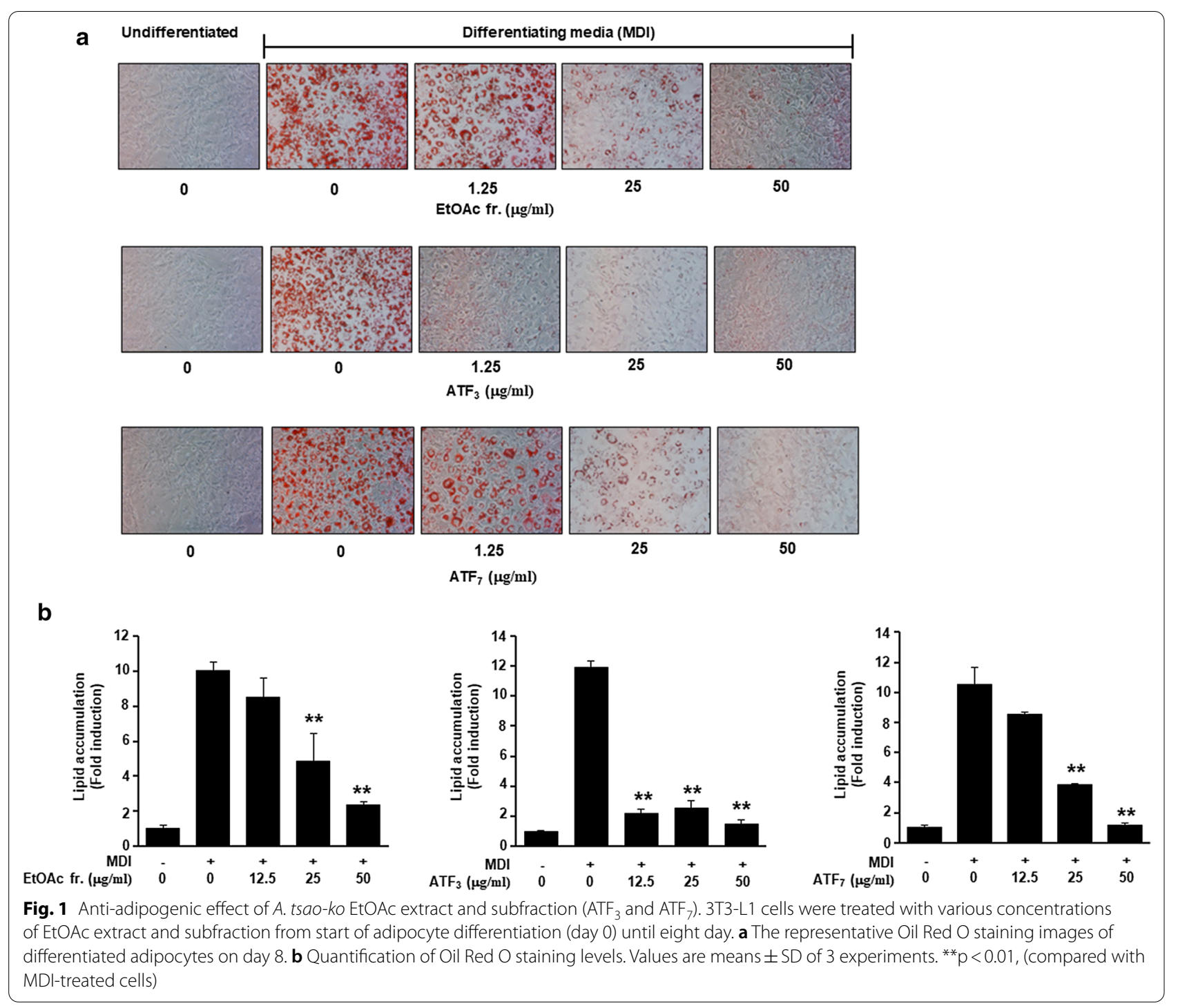

$\mathrm{mL}$ concentrations. Among them, EtOAc extract, subfractions ATF3 and ATF7 were found to the decrease in $\%$ lipid content was in concentration dependent manner (Fig. 1a, b). Of these, the fraction, $\operatorname{ATF}_{3}(3.5 \mathrm{~g})$ was subjected to MPLC over ODS eluting with a step gradient of $60-100 \% \mathrm{MeOH}$ in $\mathrm{H}_{2} \mathrm{O}$ to give nine subfractions $\left(\mathrm{ATF}_{3-1}-\mathrm{ATF}_{3-9}\right)$. Purification of the subfraction $\mathrm{ATF}_{3-3}$ by preparative HPLC $\left(\mathrm{MeCN}: \mathrm{H}_{2} \mathrm{O}, 75: 25\right.$ to $100: 0$, $40 \mathrm{~min}$ ) yielded compound 3 (10.2 $\mathrm{mg}$ ), and the purification of the subfraction $\mathrm{ATF}_{3-2}$ with $80 \% \mathrm{MeCN}$ in $\mathrm{H}_{2} \mathrm{O}$ yielded compound $4(7.8 \mathrm{mg})$. Fraction $\mathrm{ATF}_{7}$ was separated using MPLC (RediSep ${ }^{\circledR}$ Rf silica gold $120 \mathrm{~g}, 80 \mathrm{~mL} /$ min, a gradient system of $\mathrm{CH}_{2} \mathrm{Cl}_{2}$ in $\mathrm{MeOH}, 100$ min), and fractionated to 12 subfractions $\left(\mathrm{ATF}_{7-1}-\mathrm{ATF}_{7-12}\right)$. Purification of the subfractions $\mathrm{ATF}_{7-3}\left(\mathrm{MeCN}: \mathrm{H}_{2} \mathrm{O}\right.$, 25:75 to 70:30) and $\mathrm{ATF}_{7-6}\left(\mathrm{MeCN}: \mathrm{H}_{2} \mathrm{O}, 20: 80\right.$ to $\left.70: 30\right)$ by preparative HPLC yielded compound $\mathbf{1}(17.2 \mathrm{mg})$ and compound $2(5.8 \mathrm{mg})$, respectively. The purity of each compound was verified to be $>95 \%$ by HPLC.

\section{Cell culture and induction of differentiation}

3T3-L1 preadipocyte cells were purchased from the American Type Culture Collection (CL-173, ATCC, Manassas, VA, USA). Cells were maintained in 
Dulbecco's modified Eagle's medium (DMEM) supplemented with $10 \%$ bovine calf serum, $100 \mathrm{U} / \mathrm{mL}$ penicillin, and $0.1 \mathrm{mg} / \mathrm{mL}$ streptomycin (Invitrogen, Carlsbad, CA, USA) in a humidified atmosphere of $95 \%$ air and $5 \%$ $\mathrm{CO}_{2}$ at $37^{\circ} \mathrm{C}$. Two days after the cells reached confluence, they were induced with initiation media $(1 \mu \mathrm{M} M$ dexamethasone (Calbiochem, Billerica, MA, USA), $0.5 \mathrm{mM}$ 3-isobutyl-1-methylxanthine (IBMX; Calbiochem), and $1 \mu \mathrm{g} / \mathrm{mL}$ insulin (Sigma-Aldrich, St. Louis, MO, USA) in $10 \%$ fetal bovine serum (FBS; ATCC)-DMEM. On day 2 , the initiation medium was replaced with progression media $(1 \mu \mathrm{g} / \mathrm{mL}$ insulin in $10 \%$ FBS-DMEM). On days 4 and 6 , the progression medium was replaced with the maintenance media (10\% FBS-DMEM). From days 0 to 8 , the cells were treated with the effective nontoxic concentrations of the isolated compounds, identified through the 3-[4,5-dimethylthiazol-2-yl]-2,5-diphenyltetrazolium bromide (MTT) assay.

\section{Cell viability assay}

The MTT assay was used for in vitro determination of cell proliferation in 3T3-L1 cells. Cells were plated at a density of $5 \times 10^{3}$ cells per well in $100 \mu \mathrm{L}$ culture medium. One day after plating, a time-zero control plate was prepared. The isolated compounds (1-4) were applied directly, and the cells were incubated for $24 \mathrm{~h}$ in a humidified atmosphere with $5 \% \mathrm{CO}_{2}$ at $37^{\circ} \mathrm{C}$. Cell proliferation was then determined. MTT $(5 \mathrm{mg} / \mathrm{mL}$ in phosphatebuffered saline $[\mathrm{PBS}]$ ) was added to each well, followed by incubation for $3 \mathrm{~h}$. The media was removed from the wells by aspiration, and $0.1 \mathrm{~mL}$ of buffered dimethyl sulfoxide was added to each well, after which the plates were shaken. Subsequently, the absorbances were measured on a SpectraMax 190PC microplate reader at $540 \mathrm{~nm}$ (Molecular Devices, Sunnyvale, CA, USA).

\section{Oil red $\mathrm{O}$ staining}

On day 8, after induction of differentiation, the cells were stained with Oil Red O (Sigma-Aldrich, St. Louis, MO, USA). Briefly, the cells were washed with PBS and fixed with $3.7 \%$ formaldehyde in PBS for $30 \mathrm{~min}$, and then washed twice with PBS and 70\% ethanol. The cells were then stained with $0.35 \%$ Oil Red O (Sigma-Aldrich) in isopropyl alcohol/distilled water for $30 \mathrm{~min}$. Excess stain was removed by washing with $70 \%$ ethanol and PBS. Stained lipid droplets were dissolved in isopropyl alcohol containing 4\% Nonidet P-40 (Sigma-Aldrich) and quantified using an enzyme-linked immunosorbent assay reader (SPECTRAmax 190PC; Molecular Devices, Sunnyvale, CA, USA) at $510 \mathrm{~nm}$.

\section{Statistical analysis}

Data are expressed as mean \pm standard deviation (SD). The results were analyzed for statistical significance using Student's $t$-test and one-way analysis of variance. Values of $* p<0.05$ and $* * p<0.01$ were considered statistically significant.

\section{Results and discussions}

Earlier, we have shown that the ethanol extract of $A$. tsao-ko fruits inhibited the adipocyte differentiation in 3T3-L1 preadipocytes in a dose-dependent manner [26]. Therefore, in the present study, we analyzed the ethanol extract of $A$. tsao-ko fruits and isolated the phytochemical constituents. The ethanol extract was suspended in $\mathrm{H}_{2} \mathrm{O}$ and successively fractioned into the ethyl acetate fraction. The ethyl acetate-soluble fraction was further subjected to repeated column chromatography to yield four compounds $(\mathbf{1}-\mathbf{4})$ (Fig. 2). The isolated compounds were identified as methyl linolenate (1) [27], trans-nerolidol (2) [28], catechol (3) [29], and phloroacetophenone 2'-O-glucoside (myrciaphenone A, 4) [30] by MS analysis and further comparison with previously reported NMR spectroscopic data (Fig. 2 and Additional file 1: pages S3-S5). The quantitative analysis of the isolated compounds (1-4) by HPLC-PDA estimated the contents of compounds 1-4 with values of $1.89 \pm 0.04,1.68 \pm 0.02$, $0.86 \pm 0.01$, and $0.73 \pm 0.01 \mathrm{~g} / 100 \mathrm{~g}$ of the EtOH extract weight, respectively (Table 1). According to our quantitative analysis, compounds $\mathbf{1}$ and $\mathbf{2}$ were the predominant component in the fruits of $A$. tsao-ko (see Additional file 1: page S7). In previous studies based on the biological activities of the isolated compounds, it has been shown that 1 reduces the expression of microphthalmiaassociated transcription factor and tyrosinase-related proteins [31]. Compound 2, a sesquiterpene alcohol, has been shown to reduce the adhesion of HT29 cells to collagen and suppress the adhesion of HT29 cells in the presence of TNF- $\alpha$ cytokines [32]. It has also been shown to induce apoptosis by decreasing the phosphorylation of NF-kB and increasing the activity of caspases [32]. In addition, it also exhibits anti-malarial and insecticidal 


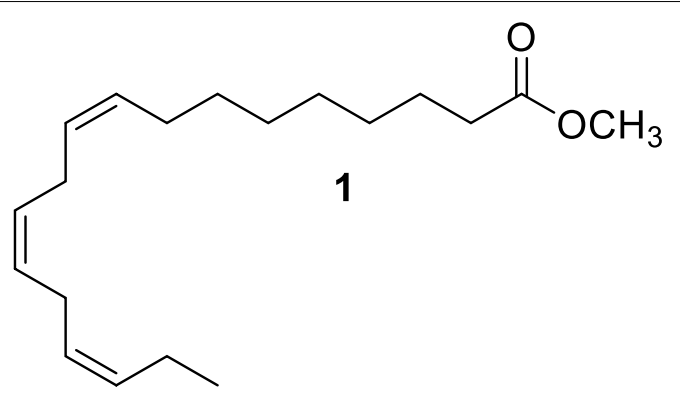<smiles>C=C[C@](C)(O)CC/C=C(/C)CCC=C(C)C</smiles><smiles>Oc1ccccc1O</smiles><smiles>CC(=O)c1c(O)cc(O)cc1O[C@@H]1O[C@H](CO)[C@@H](O)[C@H](O)[C@H]1O</smiles>

Fig. 2 Chemical structures of compounds 1-4 identified from the fruits of A. tsao-ko

Table 1 Contents (g/100 g of EtOH extract weight) of the isolated compounds (1-4) in the EtOH extract of $A$. tsao-ko

\begin{tabular}{lc}
\hline Compound & Content $^{\mathbf{a}}$ \\
\hline 1 & $1.89 \pm 0.04$ \\
2 & $1.68 \pm 0.02$ \\
3 & $0.86 \pm 0.01$ \\
4 & $0.73 \pm 0.01$ \\
\hline
\end{tabular}

a Data shown are the mean of three replicated measurements

activities [33, 34]. Compound $\mathbf{4}$, a phenolic glycoside, exhibited anti-leishmanial activity against promastigotes of Leishmania donovani [35]. However, the regulatory effects of the isolated compounds on adipocyte differentiation have not been reported to date.

In the present study, the cell viability was estimated by the MTT assay; the assay was used to determine the nontoxic concentrations of the compounds $\mathbf{1}-\mathbf{4}$ by treating 3T3-L1 cells with various concentrations $(12.5-200 \mu \mathrm{M})$ of these compounds. The results revealed that none of the compounds were cytotoxic at their effective concentrations (see Additional file 1: Figure S3); therefore, we treated the cells with compounds at this concentration for further analysis. The anti-adipogenic activities of the isolated compounds 1-4 were evaluated by assessing the fat accumulation in 3T3-L1 cells treated with the compounds. NAC ( $N$-Acetyl-L-cysteine) was used as a positive control [36, 37]. During differentiation (days 0-8), the preadipocyte cells were differentiated into mature adipocytes with cytoplasmic lipid vesicles. Furthermore, the Oil Red O staining on day 8 of differentiation and the quantification of the lipid contents revealed that the levels of Oil Red O were significantly lower in cells treated with compounds $\mathbf{1}$ and $\mathbf{3}$ than in cells treated with compounds 2 and $\mathbf{4}$ (Fig. 3a). The isolated compounds inhibited the differentiation of the 3T3-L1 cells in a concentration-dependent manner with a lower percentage of differentiated cells at a higher concentration (Fig. 3b). In addition, the inhibitory effect of compounds $\mathbf{1}$ and $\mathbf{3}$ was relatively higher than the compounds $\mathbf{2}$ and $\mathbf{4}$, and at a concentration of $50 \mu \mathrm{M}$, the compounds $\mathbf{1}$ and 3 exerted $20-50 \%$ inhibitory effect compared to control (MDI-treated cells). These findings indicated that the bioactive compounds $\mathbf{1}$ and $\mathbf{3}$ had a stronger potential to exert anti-adipogenic effects. The active constituents can be further studied for their exact mechanism of action as 


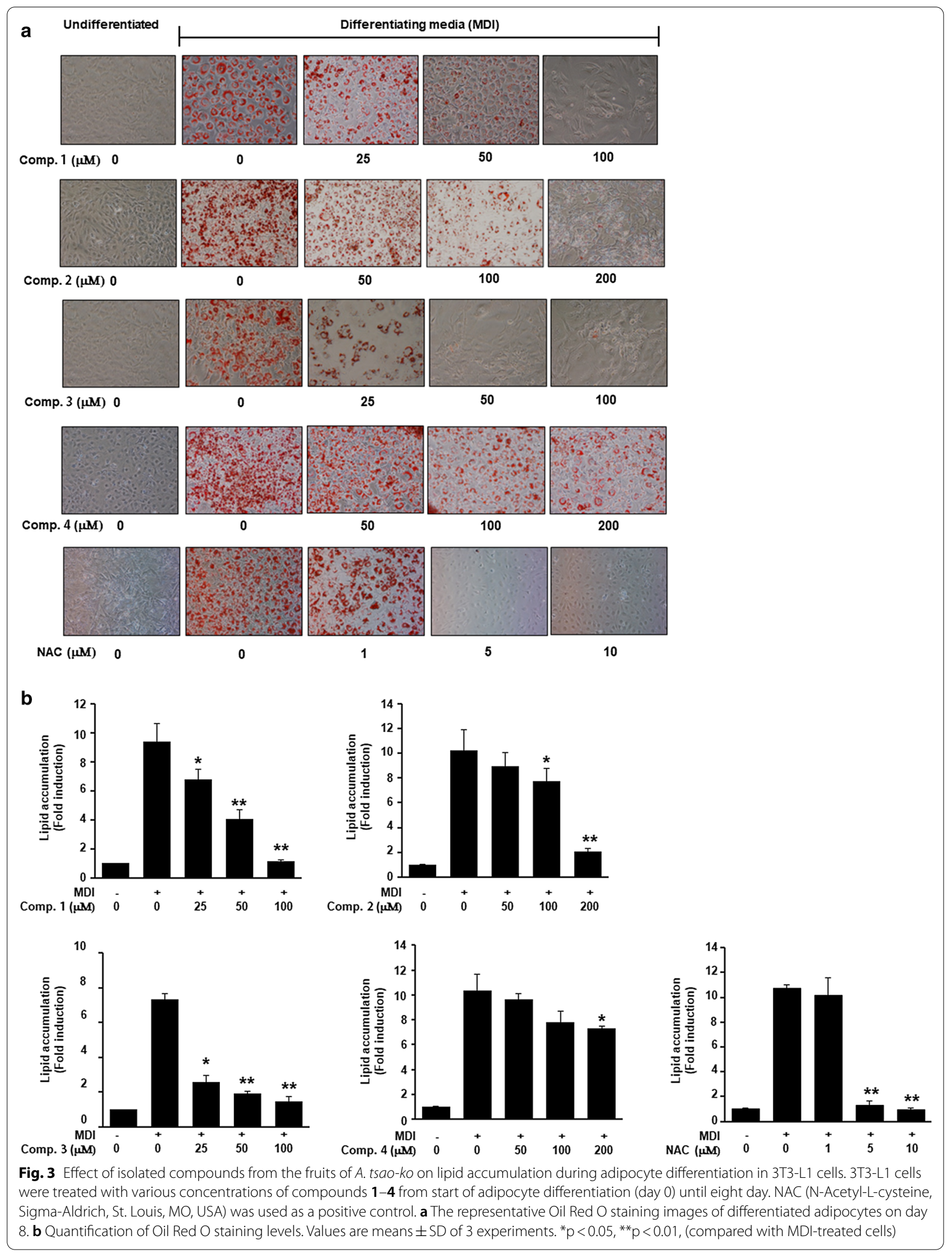


well as they can be tested in the in vivo obesity models. These biological results provide credible evidence supporting the role of the phytochemicals isolated from A. tsao-ko in regulating adipocyte differentiation, rendering A. tsao-ko as a potential source for the development of functional ingredients to treat obesity-related ailments.

\section{Supplementary Information}

The online version contains supplementary material available at https://doi. org/10.1186/s13765-020-00576-0.

Additional file 1: Additional figures.

\begin{abstract}
Abbreviations
COSY: Correlated spectroscopy; DEPT: Distortions enhancement by polarization transfer; DMEM: Dulbecco's modified Eagle's medium; HMBC: Heteronuclear multiple bond correlation; HPLC: High-performance liquid chromatography; HSQC: Heteronuclear single quantum coherence spectroscopy; MPLC: Medium-pressure liquid chromatography; MTT: 3-(4,5-Dimethylthiazol-2-yl)2,5-diphenyltetrazolium bromide; NAC: N-Acetyl-L-cysteine; NMR: Nuclear magnetic resonance; PBS: Phosphate-buffered saline; SD: Standard deviation; TLC: Thin-layer chromatography; MTT: 3-[4,5-Dimethylthiazol-2-yl]-2,5-diphenyltetrazolium bromide.
\end{abstract}

\section{Acknowledgements}

This work was carried out with the support of the Cooperative Research Program for Agriculture Science and Technology Development (Project No. PJ01323301), Rural Development Administration, Republic of Korea. We would like to thank Editage (https://www.editage.co.kr) for English language editing.

\section{Authors' contributions}

Performed the experiments: CWC, JEL, YWJ, JAL, Data analysis: SSH, WJ, YHC, HC, Wrote the manuscript: SSH, EKA, Designed and supervised the study: SSH, JSO. All authors read and approved the final manuscript.

\section{Funding}

This work was supported by a grant from Rural Development Administration (Project No. PJ01323301).

\section{Availability of data and materials}

The datasets used and/or analyzed during the current study available from the corresponding author on reasonable request.

\section{Competing interests}

The authors declare that they have no competing interests.

Received: 5 October 2020 Accepted: 2 December 2020

Published online: 08 January 2021

\section{References}

1. Fu C, Jiang Y, Guo J, Su Z (2016) Natural products with anti-obesity effects and different mechanisms of action. J Agric Food Chem 64:9571-9585

2. Blüher M (2019) Obesity: global epidemiology and pathogenesis. Nat Rev Endocrinol 15:88-298

3. Liu TT, Liu XT, Chen QX, Shi Y (2020) Lipase inhibitors for obesity: A review. Biomed Pharmacother 128:110314

4. Yun JW (2010) Possible anti-obesity therapeutics from nature - A review. Phytochemistry 71:1625-1641

5. Ezzat SM, El Bishbishy MH, Aborehab NM, Salama MM, Hasheesh A, Abdel Motaal A, Rashad H, Metwally FM (2020) Upregulation of MC4R and PPAR-a expression mediates the anti-obesity activity of Moringa oleifera Lam. in high-fat diet-induced obesity in rats. J Ethnopharmacol 251:112541
6. Lee D, Shin Y, Jang J, Park Y, Ahn J, Jeong S, Shin SS, Yoon M (2020) The herbal extract ALS-L1023 from Melissa officinalis alleviates visceral obesity and insulin resistance in obese female C57BL/6J mice. J Ethnopharmacol 253:112646

7. Lu YL, Lin SY, Fang SU, Hsieh YY, Chen CR, Wen CL, Chang Cl, Hou WC (2017) Hot-water extracts from roots of Vitis thunbergii var. taiwaniana and identified $\varepsilon$-viniferin improve obesity in high-fat diet-induced mice. J Agric Food Chem 65:2521-2529

8. Sheng Y, Zhao C, Zheng S, Mei X, Huang K, Wang G, He X (2019) Antiobesity and hypolipidemic effect of water extract from Pleurotus citrinopileatus in C57BL/6J mice. Food Sci Nutr 7:1295-1301

9. You JS, Lee YJ, Kim KS, Kim SH, Chang KJ (2014) Ethanol extract of lotus (Nelumbo nucifera) root exhibits an anti-adipogenic effect in human preadipocytes and anti-obesity and anti-oxidant effects in rats fed a high-fat diet. Nutr Res 34:258-267

10. Kim HY, Kim JH, Zuo G, Lim SS (2020) Anti-obesity effect of Melandrium firmum Rohrbach extract in 3T3-L1 cells and high-fat diet-induced obese C57BL/6N mice. Food Sci Nutr 8:2251-2261

11. Hong SS, Choi YH, Lee JA, Ahn EK, Suh JW, Oh JS (2013) Two new isoflavone glycosides from the extracts of the fungus Monascus pilosusfermented black soybean. Bull Korean Chem Soc 34:3863-3866

12. Lee JA, Cho YR, Hong SS, Ahn EK (2017) Anti-obesity activity of saringosterol isolated from Sargassum muticum (Yendo) Fensholt extract in 3T3-L1 cells. Phytother Res 31:1694-1701

13. Feng H, Tang J, Zhang P, Miao Y, Wu T, Cheng Z (2020) Anti-adipogenic 18,19-seco-ursane stereoisomers and oleane-type saponins from Ilex cornuta leaves. Phytochemistry 175:112363

14. Shi Q, Lu S, Li D, Lu J, Zhou L, Qiu M (2020) Cycloartane triterpene glycosides from rhizomes of Cimicifuga foetida $\mathrm{L}$. with lipid-lowering activity on 3T3-L1 adipocytes. Fitoterapia 145:104635

15. Lee S, Lee JC, Subedi L, Cho KH, Kim SY, Park HJ, Kim KH (2019) Bioactive compounds from the seeds of Amomum tsaoko Crevost et Lemaire, a Chinese spice as inhibitors of sphingosine kinases, SPHK1/2. RSC Adv 9:33957-33968

16. Sim S, Tan SK, Kohlenberg B, Braun NA (2019) Amomum tsao-ko-Chinese black cardamom: detailed oil composition and comparison with two other cardamom species. Nat Prod Commun 14:1934578X19857675

17. Hong SS, Lee JH, Choi YH, Jeong W, Ahn EK, Lym SH, Oh JS (2015) Amotsaokonal A-C, benzaldehyde and cycloterpenal from Amomum tsao-ko. Tetrahedron Lett 56:6681-6684

18. Liu H, Yan Q, Zou D, Bu X, Zhang B, Ma X, Leng A, Zhang H, Li D, Wang C (2018) Identification and bioactivity evaluation of ingredients from the fruits of Amomum tsaoko Crevost et Lemaire. Phytochem Lett 28:111-115

19. Zhang TT, Lu CL, Jiang JG (2016) Neuroprotective and anti-inflammatory effects of diphenylheptanes from the fruits of Amomum tsaoko, a Chinese spice. Plant Foods Hum Nutr 71:450-453

20. Zhang TT, Lu CL, Jiang JG (2015) Antioxidant and anti-tumour evaluation of compounds identified from fruit of Amomum tsaoko Crevost et Lemaire. J Funct Foods 18:423-431

21. Zhang TT, Lu CL, Jiang JG (2014) Bioactivity evaluation of ingredients identified from the fruits of Amomum tsaoko Crevost et Lemaire, a Chinese spice. Food Funct 5:1747-1754

22. Moon SS, Lee JY, Cho SC (2004) Isotsaokoin, an antifungal agent from Amomum tsao-ko. J Nat Prod 67:889-891

23. He XF, Wang HM, Geng CA, Hu J, Zhang XM, Guo YQ, Chen JJ (2020) Amomutsaokols AK, diarylheptanoids from Amomum tsao-ko and their aglucosidase inhibitory activity. Phytochemistry 177:112418

24. He XF, Zhang XK, Geng CA, Hu J, Zhang XM, Guo YQ, Chen JJ (2020) Tsaokopyranols A-M, 2,6-epoxydiarylheptanoids from Amomum tsao-ko and their a-glucosidase inhibitory activity. Bioorg Chem 96:103638

25. Kim JG, Jang H, Le TPL, Hong HR, Lee MK, Hong JT, Lee D, Hwang BY (2019) Pyranoflavanones and pyranochalcones from the fruits of Amomum tsao-ko. J Nat Prod 82:1886-1892

26. Lee JA, Park YJ, Jeong W, Hong SS, Ahn EK (2017) Anti-obesity effect of Amomum taso-ko ethanol extract in 3T3-L1 adipocytes. J Appl Biol Chem $60: 23-28$

27. Huh S, Kim YS, Jung E, Lim J, Jung KS, Kim MO, Lee J, Park D (2010) Melanogenesis inhibitory effect of fatty acid alkyl esters isolated from Oxalis triangularis. Biol Pharm Bull 33:1242-1245 
28. Blanc MC, Bradesi P, Casanova J (2005) Enantiomeric differentiation of acyclic terpenes by ${ }^{13} \mathrm{C}$ NMR spectroscopy using a chiral lanthanide shift reagent. Magn Reson Chem 43:176-179

29. Huang S, Zhang CP, Li GQ, Sun YY, Wang K, Hu FL (2014) Identification of catechol as a new marker for detecting propolis adulteration. Molecules 19:10208-10217

30. Gurbuz P, Baran MY, Demirezer LO, Guvenalp Z, Kuruuzum-Uz A (2018) Phenylacylated-flavonoids from Peucedanum chryseum. Rev Bras Farmacogn 28:228-230

31. Ko GA, Shrestha S, Kim Cho S (2018) Sageretia thea fruit extracts rich in methyl linoleate and methyl linolenate downregulate melanogenesis via the Akt/GSK3 $\beta$ signaling pathway. Nutr Res Pract 12:3-12

32. Hanušová V, Skálová L, Ambrož M, Králová V, Langhansová L, Matoušková P (2015) The effect of Myrica rubra essential oil and its components a-humulene and trans-nerolidol on adhesion and apoptosis of colorectal cancer cells. Cancer Cell Microenviron 2(4):e1058

33. Araújo MJC, Câmara CAG, Born FS, Moraes MM, Badji CA (2012) Acaricidal activity and repellency of essential oil from Piper aduncum and its components against Tetranychus urticae. Exp Appl Acarol 57:139-155
34. Goulart HR, Kimura EA, Peres VJ, Couto AS, Aquino Duarte FA, Katzin AM (2004) Terpenes arrest parasite development and inhibit biosynthesis of isoprenoids in Plasmodium falciparum. Antimicrob Agents Chemother 48:2502-2509

35. Sidana J, Neeradi D, Choudhary A, Singh S, Foley WJ, Singh IP (2013) Antileishmanial polyphenols from Corymbia maculate. J Chem Sci 125:765-775

36. Seo MJ, Lee OH, Choi HS, Lee BY (2012) Extract from edible red seaweed (Gelidium amansii) inhibits lipid accumulation and ROS production during differentiation in 3T3-L1 cells. Prev Nutr Food Sci 17:129-135

37. Pieralisi A, Martini C, Soto D, Vila MC, Calvo JC, Guerra LN (2016) N-acetylcysteine inhibits lipid accumulation in mouse embryonic adipocytes. Redox Biol 9:39-44

\section{Publisher's Note}

Springer Nature remains neutral with regard to jurisdictional claims in published maps and institutional affiliations.

\section{Submit your manuscript to a SpringerOpen ${ }^{\circ}$ journal and benefit from:}

- Convenient online submission

- Rigorous peer review

- Open access: articles freely available online

- High visibility within the field

- Retaining the copyright to your article

Submit your next manuscript at $\gg$ springeropen.com 